\title{
DESIGN OF INSET-FED TRIPLE-BAND RECTANGULAR MICROSTRIP ANTENNA FOR WIMAX, 5.5 GHZ WLAN AND LOWER X-BAND SATELLITE APPLICATIONS
}

\author{
ASHWINI C TENGLI ${ }^{1} \&$ P. M. HADALGI ${ }^{2}$ \\ ${ }^{1}$ Research Scholar, Department of P. G. Studies and Research in Applied Electronics, \\ Gulbarga University, Kalaburagi, Karnataka, India \\ ${ }^{2}$ Professor, Department of P. G. Studies and Research in Applied Electronics, \\ Gulbarga University, Kalaburagi, Karnataka, India
}

\begin{abstract}
In this paper, a novel design of triple-band inset-fed rectangular micro strip antenna with T-shapeslitloade disproposed for WiMAX, $5.5 \mathrm{GHz}$ WLAN and lower X-band satellite applications is presnted. The proposed antenna consists of rectangular radiating elements with a $T$-shape slot loaded, which is excited through simple $50 \Omega$ in set microstrip feed-line. The antenna configuration is printed on a $40 \times 30 \times 1.6 \mathrm{~mm} 3$ low cost FR-4 dielectric material having permittivity of 4.2 which includes ground plane. To obtain a triple-band operation, a narrow Tshaperectangularslitisembeddedat the top non-radiatingedge of the radiating patch. The proposed antennaresonatesat three frequencies of 3.11, 5.5 and $6.30 \mathrm{GHz}$ with $-10 \mathrm{~dB}$ impedancebandwidths of $\mathrm{B} \mathrm{W}_{1}=6 \%(2.91-3.05 \mathrm{GHz})$, B $\mathrm{W}_{2}=$ $7.27 \%(5.34-5.69 \mathrm{GHz})$ and $\mathrm{BW}=4.14 \%(6.13-6.41 \mathrm{GHz})$. The simulation results are obtained by utilizing $3 \mathrm{D}$ full-wave high frequency structural simulator (HFSS) for comparison with experimental results. Acceptable agreement isobserved between the both experimental and simulation results. The obtained results indicatethat, the propose dantenna shows broadside radiation characteristics a three operating frequency bands. Owing to its simple antenna structure and its radiation characteristics, it is highly recommendable for applications at which adequately covers the frequency bands of WiMAX, $5.5 \mathrm{GHz}$ WLAN and X-band lower satellite communication (6-6.5 GHz). The details of antenna designing and results are presented and discussed.

KEYWORDS: Triple-Band Antenna, Inset-fed, WiMAX, WLAN \& X-Band Satellite Communication
\end{abstract}

Received: Jun 20, 2017; Accepted: Jul 08, 2017; Published: Jul 20, 2017; Paper Id.: IJEEERAUG20174

\section{INTRODUCTION}

In recent decades, the Micro Strip Antennas (MSAs) have played very important role in modern wireless communication due to its several attractive features, for instance, they have compact size, light weight, lowcost, easilyintegrated with planar and non-planar MMICs and conformal structure [1]. Also, the MSAs are becoming one of the essential candidates for bothmilitary (satellites, spacecraft and guided missiles) and commercial applications (wireless communication systems and mobile technology) [2-7]. Since then, the rapid advancement of microstrip antenna technology is taking place in personal wireless communication technologies such as global positioning satellite (GPS) transmitters, Wireless Local Area Network (WLAN), Bluetooth gadgets and demands an inter connectivity of more than one frequency band into a single compact planar design. To over come this major problem, a low cost compact planar printed multiband microstripantennas with acceptable radiation characteristics are required [8]. Usually, the structure of the conductingradiating patch of the antenna can be anyshape. In practice, rectangular, elliptical, square, circular, triangular shapes are considered for antenna design 
[9-12]. The modern mobile gadgets are required to support different services and multi standards, which operate at different frequency spectrum. Recently, compact planarantennas have been developed for single, dual, triple and quadband operation which covers the typical frequency bands that include GPS (1.227 GHz, 1.575 GHz), PCS, (1.850-1.990 GHz), UMTS (1.920-2.170 GHz), IMT-2000, DCS, WLAN-IEEE bands such as Wi-Fi (2.4-2.48 GHz, 5.15-5.35 GHz, 5.725-5.850 GHz), and WiMAX (2.5-2.69 GHz, 3.4-3.69 GHz, 5.25-5.85 GHz) [13-19]. The ability to provide an antenna small size is an important requirement for the design and development of multiband operation.

In thispaper, we present a new planarinset-fed rectangular microstrip antenna loadedwith T-shape slit at the top side of the radiating patch. The proposed antenna is designed, whichis capable to work for triple-band operation covering WiMAX, WLAN and X-band satellite communication. Details of the proposed antenna design and, experimental and simulation results are presented and discussed.

\section{Design of the Antenna}

Figure 1 show the geometry of the proposed triple band antenna. The antenna structure is printed on $40 \times 30 \mathrm{~mm} 2$ lowcost FR-4 epoxy substrate, with the relative permittivity $\varepsilon_{\mathrm{r}}=4.4$ and having thickness of $\mathrm{h}=1.6 \mathrm{~mm}$. The antenna is rectangular radiating patch having a dimensions of width $\mathrm{W}=22.8 \mathrm{~mm}$ and length $\mathrm{L}=17.4 \mathrm{~mm}$ with a narrow $\mathrm{T}$-shape slit at top of the radiating patch. The proposed antenna is fed by simple $50 \Omega$ inset-fed microstrip feed-line has dimensions of length $\mathrm{L}_{\mathrm{f}}=16.34 \mathrm{~mm}$ and $\mathrm{W}_{\mathrm{f}}=3.06 \mathrm{~mm}$ on the top side of the substrate and bottom of the substrate, the $40 \times 30 \mathrm{~mm}^{2}$ ground plane used. For a better impedance matching between radiating patch and simple $50 \Omega$ in set-fed microstrip feed-line is used, where, width of $\mathrm{I}_{\mathrm{W}}=1.53 \mathrm{~mm}$ and length of $\mathrm{I}_{\mathrm{L}}=5.78 \mathrm{~mm}$ are chosen to achieve the optimum results.

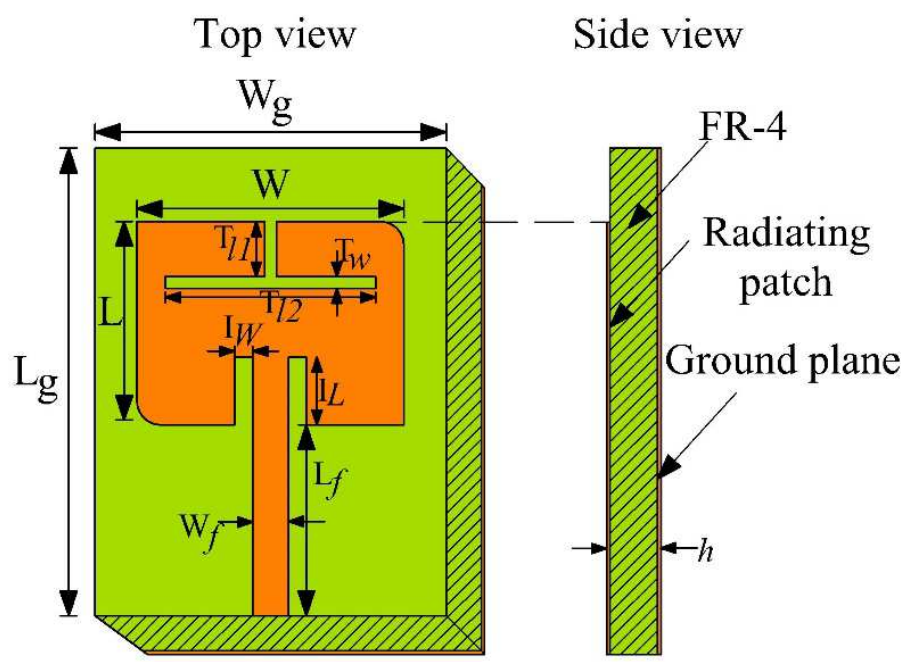

Figure 1: Geometry of the Proposed Triple-Band Antenna

To obtain a triple-band operation, the conventional rectangular radiating element is modified by truncating the opposite top and bottom corners of the radiating patches and embedding a narrow T-shape slit at the top of the radiating patch. The prototype of the proposed antenna is designed by using commercial electromagnetics ANSYS HFSS simulation tool [20]. The optimized antenna parameters and its dimensions of the proposed antenna are given in Table 1.

Table 1: Optimized Dimensions and Parameters of the Proposedantenna

\begin{tabular}{|l|c|c|c|c|c|c|c|c|c|c|c|c|}
\hline Antenna Parameters & $\mathbf{W}_{\mathbf{g}}$ & $\mathbf{L}_{\mathbf{g}}$ & $\mathbf{W}$ & $\mathbf{L}$ & $\mathbf{W}_{\mathbf{f}}$ & $\mathbf{L}_{\mathbf{f}}$ & $\mathbf{T}_{\mathbf{1} 1}$ & $\mathbf{T}_{\mathbf{1} 2}$ & $\mathbf{T}_{\mathbf{W}}$ & $\mathbf{I}_{\mathbf{W}}$ & $\mathbf{I}_{\mathbf{L}}$ & $\mathbf{H}$ \\
\hline Dimensions in mm & 30 & 40 & 22.8 & 17.4 & 3.06 & 16.34 & 4.74 & 18 & 1 & 1.53 & 5.78 & 1.6 \\
\hline
\end{tabular}




\section{RESULTS AND DISCUSSIONS}

Figure 2 shows the variation of return loss versus characteristics of the proposed antenna. From this figure, it is clear that, the proposed antenna resonate for three frequencies modes at $\mathrm{f}_{\mathrm{r} 1}, \mathrm{f}_{\mathrm{r} 2}$ and $\mathrm{f}_{\mathrm{r} 3}$ with -10 dB return loss and impedance band widths of $\mathrm{BW}_{1}=6 \%(2.91-3.05 \mathrm{GHz}), \mathrm{BW}_{2}=7.27 \%(5.34-5.69 \mathrm{GHz})$ and $\mathrm{BW}_{3}=4.14 \%$ (6.13-6.41GHz), respectively. The first resonant band with $-10 \mathrm{~dB}$ impedance band width of $\mathrm{BW}_{1}=6 \%(2.91-3.05 \mathrm{GHz})$ is wide enough to cover the WiMAX communication system. It is also observed from Figure 2 that, the second and third resonant frequency bands with $-10 \mathrm{~dB}$ impedance band widths of $\mathrm{BW}_{2}=7.27 \%(5.34-5.69 \mathrm{GHz})$ and $\mathrm{BW}_{3}=4.14 \%(6.13-6.41 \mathrm{GHz})$ which is sufficient to cover the $5.5 \mathrm{GHz}$ WLAN narrow band and lower X-band satellite communication bands, respectively. The Ansoft HFSS simulation result of the proposed triple-band is also shown in Figure 3. The reasonable agreement is obtained between experimental and simulation results.

Further, from the experimental and simulated return loss plot, which is shown in Figure 2, it is clear that, by embedding a narrow equal widths of T-shape rectangular slit at the top side of non-radiating edge of the rectangular radiating patch with the length in terms of $\lambda_{0}$. The obtained resonant frequency bands i.e. $3.11 \mathrm{GHz}, 5.5 \mathrm{GHz}$ and $6.30 \mathrm{GHz}$ are influenced by the unequal arm lengths and equal width of the vertical and horizontal arms of the T-shaped slit. The width $T_{w}$ is $1 \mathrm{~mm}$ of horizontal and vertical arms of the T-shape slit. The lengths of two T-shapeslits $T l_{1}$ and $T l_{2}$ of vertical and horizontal arms equal to $4.74 \mathrm{~mm}$ and $18 \mathrm{~mm}$, respectively, which are optimum design parameters to achieve WiMAX, 5.5 GHz WLAN and lower X-band applications.

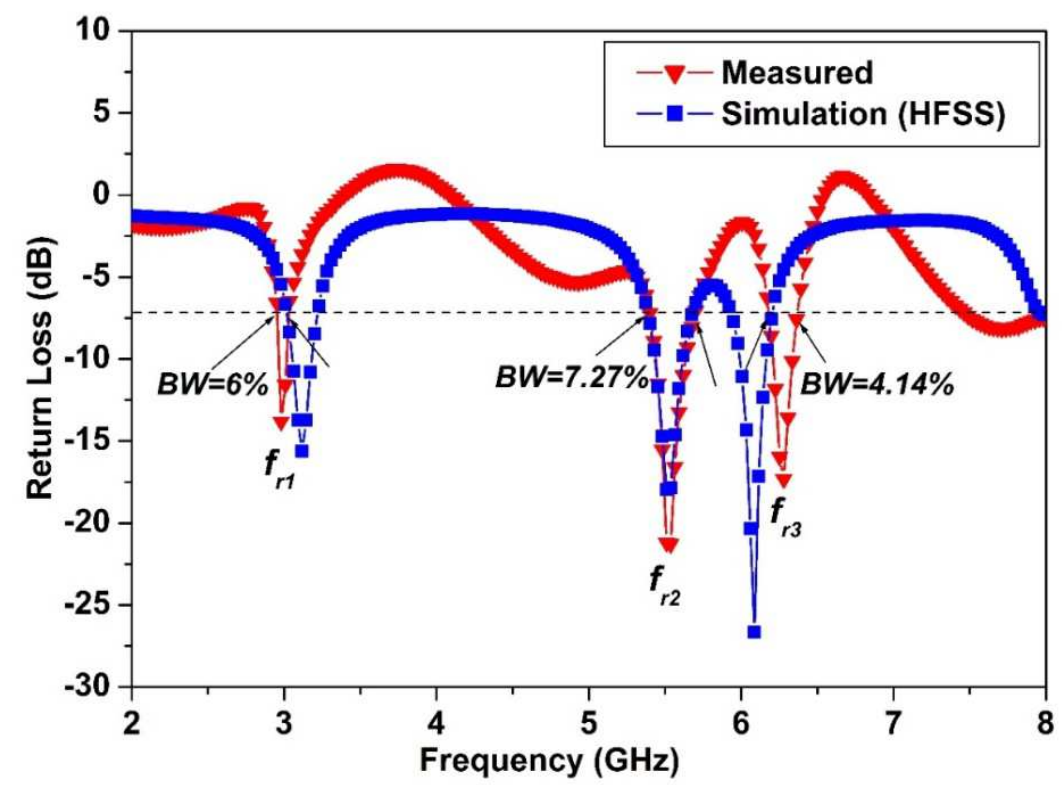

Figure 2: Variation of Return Loss Versus Frequency of the Proposed Multiband Antenna 


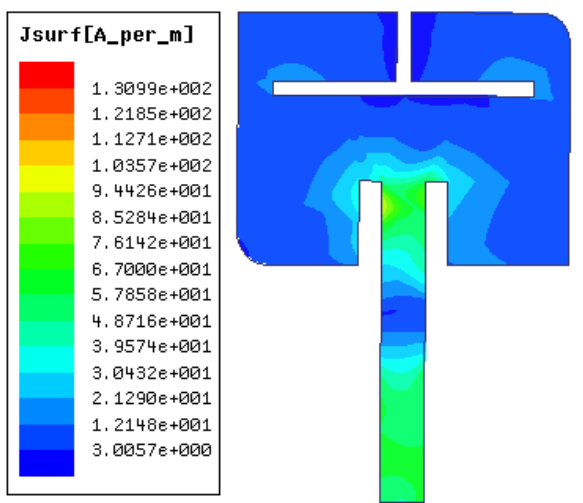

(a)
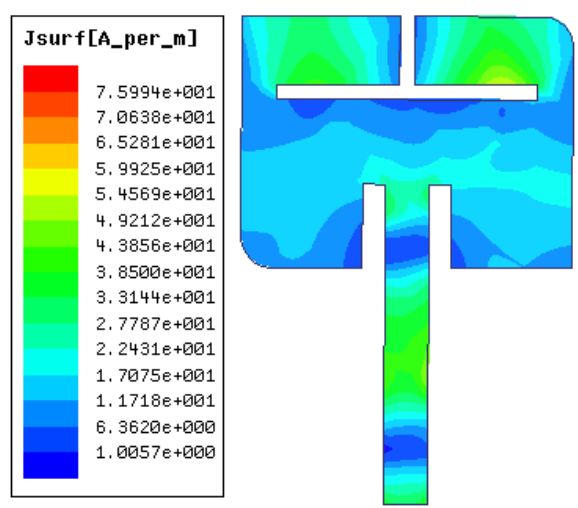

(c)
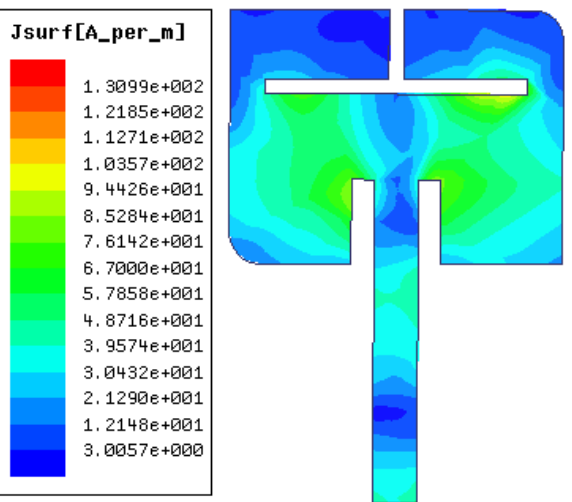

(b)
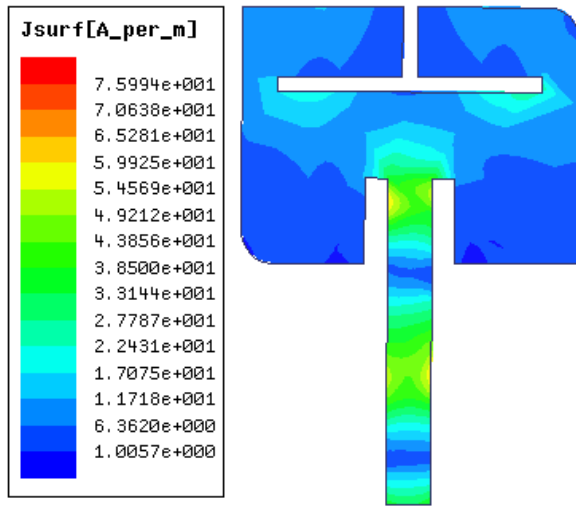

(d)

Figure 3: Surface Current Distributions of the Proposed Triple-Band Antenna are Observedat (a) $3.11 \mathrm{GHz}$, (b) $5.5 \mathrm{GHz}$, (c) $5.8 \mathrm{GHz}$ and (d) $6.30 \mathrm{GHz}$

The simulated surface current field distribution on the radiating patch of the proposed antenna is shown in Figure 3(a)-3(d). From the Figures 3 (a), (b) and (d), it is clear that the surface current field distribution, mostly concerned at the entire radiating patch and $50 \Omega$ microstrip line feed except at the T-shaped slit, which are actually observed at respective resonating bands i.e. 3.11, 5.5, and $6.30 \mathrm{GHz}$. But, from the Figure 3(d), it is evident that the more current is accumulated around the T-shaped slit, except the radiating patch which is observed non resonating frequency mode of $5.80 \mathrm{GHz}$. This phenomenon leads to confirm of the good radiation performance of the proposed antennas.

The desired normalized co-polar and cross-polar plots in both E-plane and H-plane radiation patterns at the resonating frequency bands of the proposed antenna is as shown in Figure 4(a)-(c). The radiation patterns are observed to be broadside in nature and linearly polarized at respective resonating frequency bands. Also, the proposed antenna exhibits similar radiation characteristics in its remaining operating bands. In this paper, the gain of the proposed antenna is calculated by absolute gain method. The power transmitted $\left(\mathrm{P}_{t}\right)$ by horn antenna and power received $\left(\mathrm{P}_{\mathrm{r}}\right)$ by antenna under test (AUT) are measured separately. The gain $(\mathrm{G}) \mathrm{dB}$ of the proposed triple-band antenna is calculated by using the following equation,

$$
\text { (G) } d B=10 \log \left(\frac{P_{r}}{P_{t}}\right)-\left(G_{t}\right) d B-20 \log \left(\frac{\lambda_{0}}{4 \pi R}\right) d B
$$

where, $G_{t}$ is the gain of the pyramidal horn antenna and ' $R$ ' is the distance between the transmitting antenna and the AUT. The maximum gain of the proposed antenna is measured at their operating frequency bands, and is found to be 
2.7, 4.13 and $3.89 \mathrm{~dB}$, respectively. Figure 5 shows the simulated gain of the proposed antenna. From this figure it is noted that, the negative gain is observed at lower frequencies, but at the resonating frequency bands of 3.11, 5.4 and $6.30 \mathrm{GHz}$, a maximum gain of 2.7, 4.5 and $4 \mathrm{~dB}$ are obtained. It is also evident from this figure that, the average gain of $3.5 \mathrm{~dB}$ is observed throughout the operating bands. The experimental gain values of the proposed antenna, which are measured at respective resonating frequency bands are approximately equal when compared to simulated results.
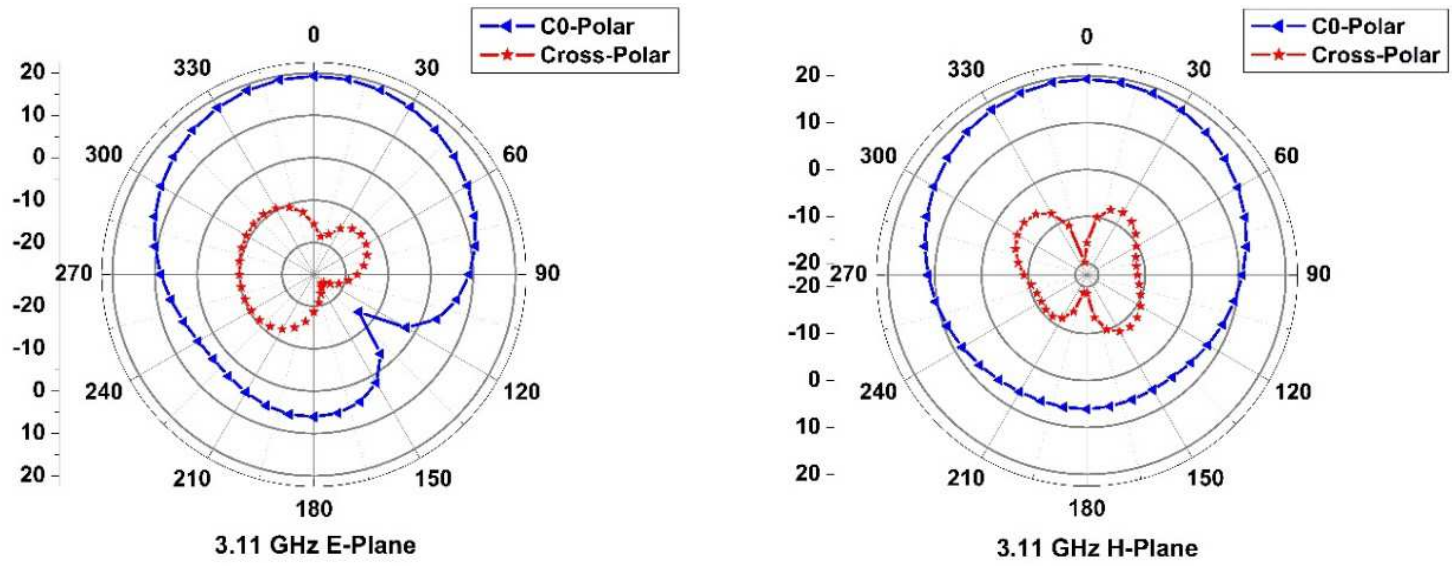

(a)
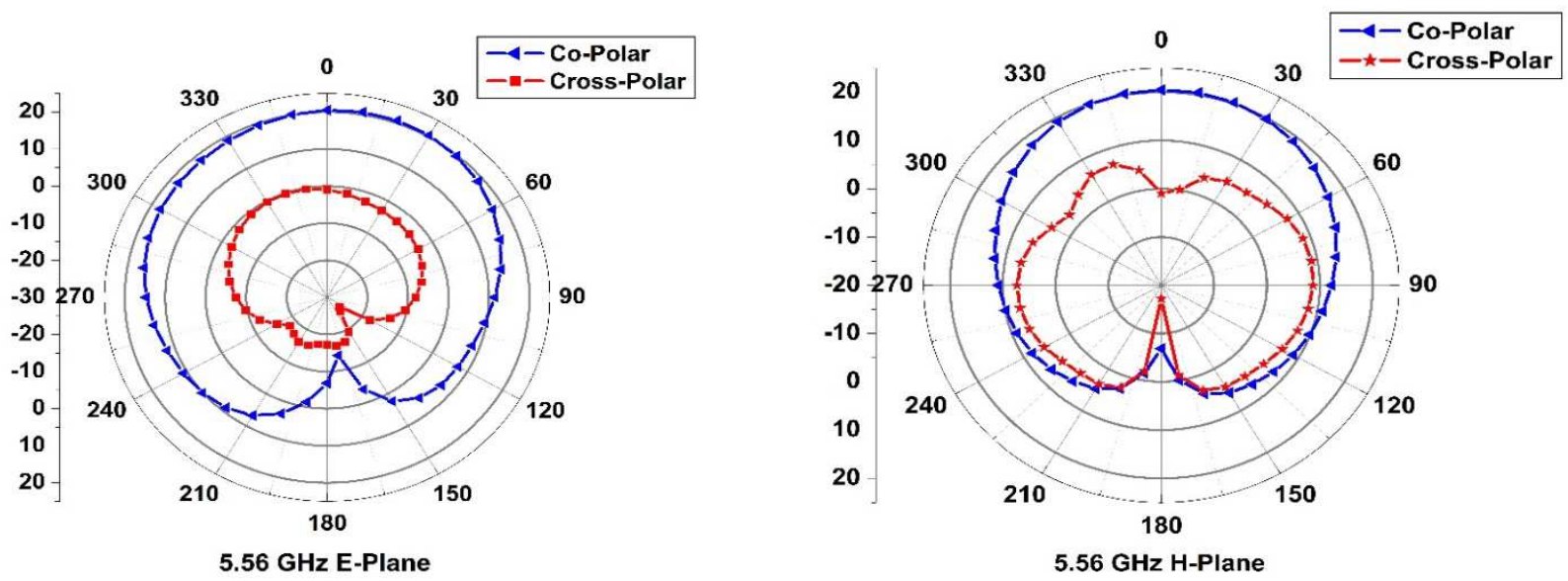

(b)
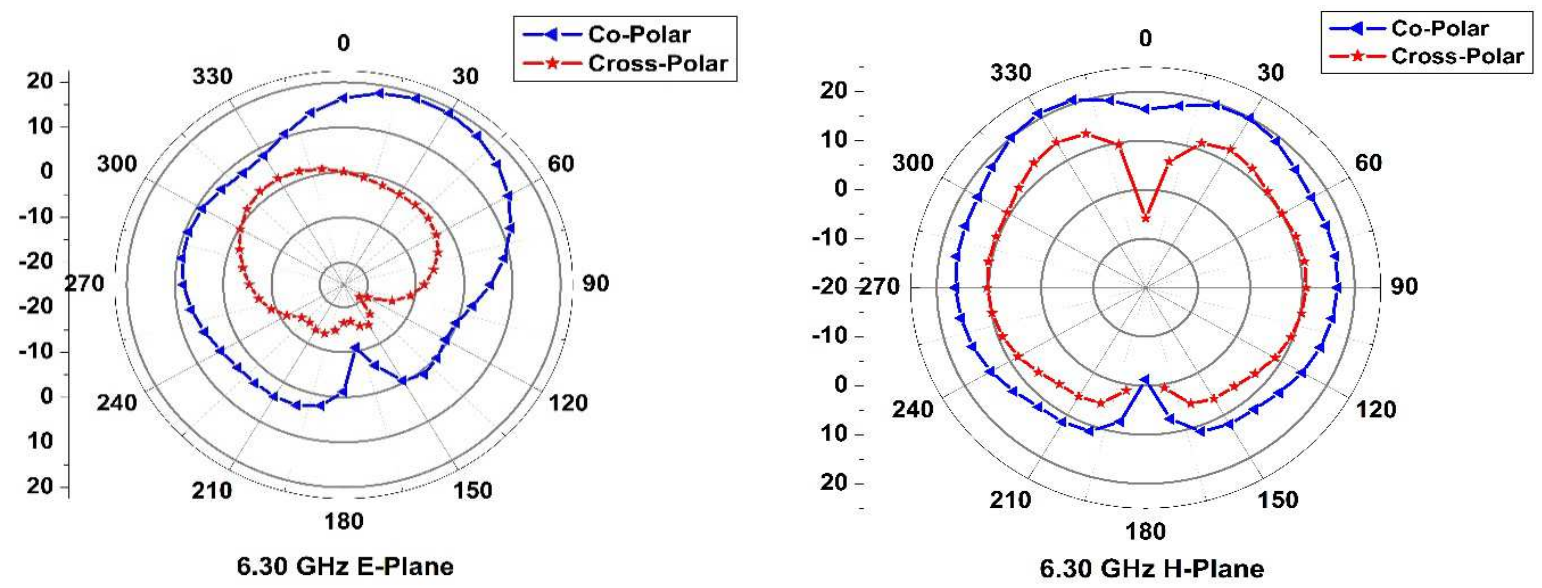

(c)

Figure 4: Typicalco-Polar and Cross-Polar in E Plane, and H-Plane Radiation Patterns of the Proposed Antenna Measured at (a) $3.11 \mathrm{GHz}$, (b) $5.56 \mathrm{GHz}$ and (c) $6.30 \mathrm{GHz}$ 


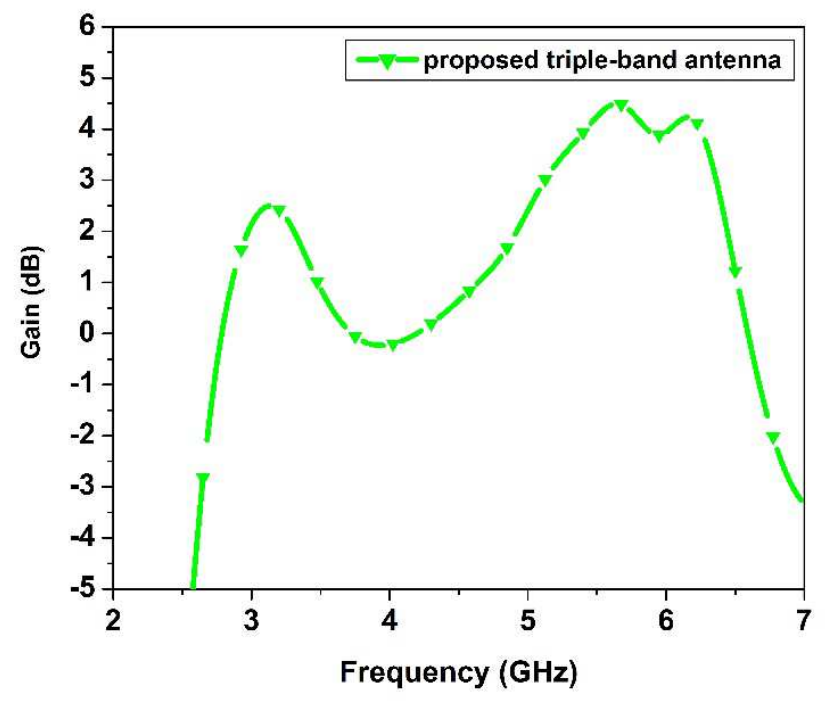

Figure 5: Gain of the Proposed Triple-Band Antenna

\section{CONCLUSIONS}

A simple novel design of inset-fed loaded rectangular microstrip antenna with embedding a T-shaped slit is proposed for triple-band operation which is suitable for WiMAX, 5.5 GHz WLAN and lower X-band satellite communication system applications. By inserting the equal arm width of a narrow T-shaped slit at the top of the radiating patch, the triple bands are achieved which are resonant at 3.11, 5.5 and $6.30 \mathrm{GHz}$ with an acceptable -10dB impedance band widths of $\mathrm{BW}_{1}=6 \%, \mathrm{BW}_{2}=7.27 \%$ and $\mathrm{BW}_{3}=4.14 \%$, respectively. Further, the proposed antenna shows a broadside radiation characteristics with the maximum gain of $2.6 \mathrm{~dB}, 4.5 \mathrm{~dB}$ and $4 \mathrm{~dB}$ are observed at resonant frequency bands. The proposed antenna is simple in its construction, and is compact in size, easily mounted with other MMICs and use with low cost substrate material. Hence, the proposed antenna is good choice for the multi band wireless communication systems applications, such as WiMAX, 5.5 GHz WLAN, and X-band satellite communication.

\section{ACKNOWLEDGEMENTS}

The authors would like to express their sincere gratitude the authorities of Dept. of Science \&Technology (DST), Govt. of India, New Delhi, for sanctioning the Vector Network Analyzer (VNA) to the Department of Applied Electronics, Gulbarga University, Kalaburagiunder the FIST project.

\section{REFERENCES}

1. Constantine A Balanis, (2005).AntennaTheoryAnalysis and Design, John Wiley\& Sons

2. I.J.Bahl and P.Bhartia, (1980).MicrostripAntennas, Boston : Artech House

3. GirishKumar and K. P. Ray, (2003). Broadband microstripantennas, London :Artech House

4. M. Pozar, (1985). A microstripantenna aperture coupled to a microstripline, Electron. Lett., 21, 49-50.

5. G. Kumar and K. P. Ray, (2003). Broadband microstripantennas, London: Artech House

6. Amit A. Deshmukh and K. P. Ray, (2011). Broadband proximity-fedmodifiedrectangularmicrostripantennas, IEEE Antennas and Propogat. Mag., 53(5), 41-56

7. Choi, S.H., Park, J.K., Kim, S.K., and Kim, H.S., (2004). Design of dual-band antenna for the ISM band using a 
backedmicrostrip line, Microw. Opt.Technol. Lett., 41(6), 457-460

8. C. M. Su, W. S. Chen, and K. L. Wong, (2003). Compact dual-bandmetal-plate antennafor 2.4/5.2-GHz WLAN operation, Microw. Opt.Technol. Lett., 38, 113-115

9. W. C. Liu, C. M. Wu, and Y. Dai, (2011). Design of triple-frequencymicrostrip-fed monopole antennausingdefectedground structure, IEEETrans. AntennasPropag.,59(7), 2457-2463

10. Y.B. Kwon, J.I. Moon, and S. O. Park, (2003). An internal triple-band planarinverted-F antenna, IEEE Antennas Wireless Propag. Lett., 2,341-344

11. Kin Lu Wong and WenHsiu Hsu, (2001). A broad-bandrectangular patch antennawith pair of wideslits, IEEE Trans. AntennasPropagat, 49(9), 1345-1347

12. Sarkar. I, Sarkar. P. P and Chowdhury. S. K, (2009). A novel compact, microstripantennawithmultifrequencyoperation,International Seminar/Workshop on Direct and Inverse Problems of Electromagnetic and AcousticWaveTheory, DIPED-2009, 1, 147-151

13. Bao F. Mang and Yuen T. Lo, (1984). Microstripantennas for dual-frequencyoperation, IEEE, Trans. AntennasPropogat., AP32(9), 526-530

14. D. Ahn, J. S. Park, C. S. Kim, J. Kim, Y. X. Qian, and T. Itoh, (2001). A design of the low-passfilterusing the novelmicrostripdefectedground structure, IEEE TransMicrowaveTheoryTech. 49, 86-93

15. Yan Zhou and Claire Gu, (2009). A modifiedtwo-strip monopole antennafor WiFi and WiMAX applications, MicrowaveOpt.TechnolLett., 51(12), 2884-2886

16. Joong Han Yoon, Young ChulRhee andYean Kil Jang, (2012). Compact monopole antenna design for WLAN/WiMAX tripleband operations, MicrowaveOpt.Technol.Lett., 54(8)

17. R. Li, B. Pan, J. Laskar, and M. M. Tentzeris, (2008). A novellow-profilebroadband dual-frequencyplanarantenna for wirelesshandsets, IEEETrans. AntennasPropag., 56(4), 1155-1162

18. R. K. Raja, M. Joseph, B. Paul and P. Mohanan, (2005). Compact planarmultibandantenna for GPS, DCS, 2.4/5.8 GHz WLAN applications, Electron. Lett.,41(6)

19. Z. X. Yuan, Y. Z. Yin, Y. Ding, B. Li and J. J. Xie, (2012). Multibandprinted and double-sideddipoleantenna for WLAN/WiMAX applications, MicrowaveOpt.Technol.Lett., 54(4)

20. Ansoft Corporation, Ansoft High Frequency Structure Simulation(HFSS), Ver. 13, Ansoft Corporation, Pittsburgh, PA, 2010. 
